\title{
One Year Follow up in Ischemic Brain Injury and the Role of Alzheimer Factors
}

\author{
M. JABLOŃSKI ${ }^{1}$, R. MACIEJEWSKI ${ }^{2}$, S. JANUSZEWSKI ${ }^{3}$, M. ULAMEK ${ }^{3}$, R. PLUTA ${ }^{3}$ \\ ${ }^{1}$ Department of Ortopedics and Rehabilitation, Lublin Medical University, Lublin, Poland, \\ ${ }^{2}$ Department of Human Anatomy, Lublin Medical University, Lublin, Poland, ${ }^{3}$ Laboratory of \\ Ischemic and Neurodegenerative Brain Research, Mossakowski Medical Research Centre, Polish \\ Academy of Sciences, Warsaw, Poland
}

Received October 20, 2010

Accepted March 30, 2011

On-line July 19, 2011

\begin{abstract}
Summary
Ongoing interest in brain ischemia research has provided data showing that ischemia may be involved in the pathogenesis of Alzheimer disease. Brain ischemia in the rat produces a stereotyped pattern of selective neuronal degeneration, which mimics early Alzheimer disease pathology. The objective of this study was to further develop and characterize cardiac arrest model in rats, which provides practical way to analyze Alzheimertype neurodegeneration. Rats were made ischemic by cardiac arrest. Blood-brain barrier (BBB) insufficiency, accumulation of different parts of amyloid precursor protein (APP) and platelets inside and outside BBB vessels were investigated in ischemic brain up to 1-year survival. Ischemic brain tissue demonstrated haphazard BBB changes. Toxic fragments of APP deposits were associated with the BBB vessels. Moreover our study revealed platelet aggregates in- and outside BBB vessels. Toxic parts of APP and platelet aggregates correlated very well with BBB permeability. Progressive injury of the ischemic brain parenchyma may be caused not only by a degeneration of neurons destroyed during ischemia but also by chronic damage in BBB. Chronic ischemic BBB insufficiency with accumulation of toxic components of APP in the brain tissue perivascular space, may gradually over a lifetime, progress to brain atrophy and to full blown Alzheimer-type pathology.
\end{abstract}

\section{Key words}

Brain ischemia • Blood-brain barrier • Amyloid precursor protein • Platelets • Dementia

\section{Corresponding author}

R. Pluta, Laboratory of Ischemic and Neurodegenerative Brain
Research, Mossakowski Medical Research Centre, Polish Academy of Sciences, 02-106 Warsaw, Pawińskiego 5 Str., Poland. Fax: 4822-668-55-32. E-mail: pluta@cmdik.pan.pl

\section{Introduction}

Ongoing interest in brain ischemia study has provided data showing that ischemia may be involved in the pathogenesis of Alzheimer disease (Pluta et al. 1994c, 2010b, Zlokovic 2002, Malm and Koistinaho 2007, Pluta 2007, Yang and Simpkins 2007). Experimental brain ischemia produces a stereotyped pattern of selective neuronal degeneration, which imitates with Alzheimer disease neuropathology (Pluta 2000, Pluta et al. 2009, 2010a). Some animals that survive 1 year after brain ischemia developed brain atrophy that is indicative of active, slowly progressing pathological processes (Hossmann et al. 1987, Andjus et al. 2010). More recently, it has become recognized by us that pathological processes continue well beyond the acute stage (Pluta 2000, 2002, Jabłoński et al. 2010, Pluta et al. 2010a). The profile of brain pathology, which is observed in an experimental brain ischemia, shares a commonality with degeneration processes in Alzheimer disease (Table 1) (Yang and Simpkins 2007, Pluta et al. 2009). The objective of this study was to further develop and characterize cardiac arrest model in rats (Pluta et al. 1991) that provides practical way to analyze Alzheimertype neurodegeneration. On the other hand, this model provides a bridge between experimental and clinical research that greatly facilitates the interpretation of 
complex disease processes i.e. in dementia after brain ischemia and Alzheimer disease.

Table 1. Alzheimer neuropathology in ischemic brain with 1 year survival.

\begin{tabular}{lc}
\hline \multicolumn{1}{c}{ Kind of pathology } & $\begin{array}{c}\text { Ischemic } \\
\text { brain }\end{array}$ \\
\hline Blood-brain barrier & $\uparrow$ \\
N-terminal of amyloid precursor protein & - \\
B-amyloid peptide & + \\
C-terminal of amyloid precursor protein & + \\
Tau protein & + \\
Platelets & $\uparrow$ \\
Amyloid plaques & + \\
Neuroinflammation & $\uparrow$ \\
Brain cells death & $\uparrow$ \\
Gliosis & $\uparrow$ \\
Leukoaraiosis & $\uparrow$ \\
Atrophy of hippocampus & $\uparrow$ \\
Atrophy of cortex & $\uparrow$ \\
Atrophy of brain & $\uparrow$ \\
Dementia & $\uparrow$ \\
\hline
\end{tabular}

Pathology: - absent; + present; $\uparrow$ progressing.

\section{Materials and Methods}

We used 16 females Wistar rats (3 months old, weight 150-180 g). The animals were divided for two groups. First group with 10-min cardiac arrest $(n=8)$ (Pluta et al. 1991) and second was used as sham-operated control $(\mathrm{n}=8)$. All rats underwent behavioral tests: neurological examination, rotarod, elevated plus maze, open field, novel object recognition and object location memory, T-maze and Morris water maze 1 year after brain ischemia (Jabłoński et al. 2010, Pluta et al. 2010c). At the end of 1 year observation brains of animals were fixed by perfusion (Pluta et al. 1991, 1994c, 1996). Some brains were used for blood-brain barrier investigation (Pluta et al. 1994a,b), other were stained for evaluation of the ischemic neuronal pathology and amyloid precursor protein changes (Pluta 2000, 2002) and small pieces were used for platelets studies in electron microscope (Pluta et al. 1994a). Animal experimentation was in accordance with the European Guidelines on Laboratory Animal care. All procedures were approved by the First Warsaw Ethical Committee on Animal Research.

\section{Results}

\section{Behavioral examination}

One year after brain ischemia rats showed: hearing dysfunction, hyperactivity, problems with adaptation to new environment, reduced anxiety, learning and memory impairment in a battery of hipocamppal dependent tests.

\section{Blood-brain barrier examination}

One year following brain ischemia brain areas contained single and scattered regions of horseradish peroxidase extravasations (Fig. 1A). Horseradish peroxidase extravasations involved small arterioles, venules and intraparenchymal capillaries and leptomeningeal pial microvessels. Extravasated horseradish peroxidase appeared to be restricted to branches and bifurcations of leaking blood-brain barrier vessels. In summary ischemic brain presented random/ haphazard blood-brain barrier permeability mainly in the hippocampus, brain cortex and white matter. Control brains showed no horseradish peroxidase staining outside blood-brain barrier microvessels.

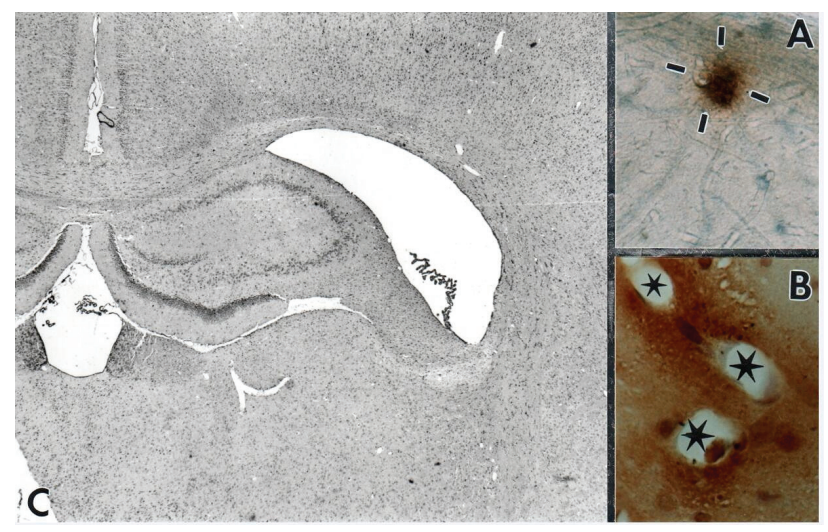

Fig. 1. A. Rat cortex showing extravasations of horseradish peroxidase (strokes). X 100. B. C-terminal amyloid precursor protein deposits around vessels (asterisks) in the corpus callosum. X 200. C. Enlargement of the ventricular system with atrophy of hippocampus and in atrophic hippocampus complete disappearance of the CA1 area. (H\&E) X 20.

\section{Amyloid precursor protein examination}

One year after brain ischemia staining only for the neurotoxic $\beta$-amyloid peptide and C-terminal of amyloid precursor protein was noted (Fig. 1B, Table 1). Multiple and abundant $\beta$-amyloid peptide and C-terminal of amyloid precursor protein accumulations embraced or adjoined the blood-brain barrier neurovessels (Fig. 1B). The staining size was different and irregular in shape. 
Mircovessels lumens and their inner and outer side of walls were also stained. After ischemia brains demonstrated widespread and multifocal diffuse C-terminal of amyloid precursor protein $/ \beta$-amyloid peptide plaques predominantly in the hippocampus, brain and entorhinal cortex, and corpus callosum (Fig. 1B) or around the lateral ventricles. Endothelial, pericyte, ependymal and neuronal cells were labeled, too. Additionally astrocytes exhibited strong reaction for C-terminal of amyloid precursor protein and $\beta$-amyloid peptide. Especially perivascular astrocytes showed very intense labeling of numerous very long, delicate, thin processes, which embraced or adjoined the capillaries. The halo of $\beta$-amyloid peptide and C-terminal of amyloid precursor protein immunoreactivity in the perivascular space of blood-brain barrier vessels suggests that both proteins can easy cross walls of blood-brain barrier neurovessels (Fig. 1B). In general, perivascular deposits of different fragments of amyloid precursor protein took the same forms as extravasated horseradish peroxidase. Above kind of pathology was not observed in shamoperated rats.

\section{Platelets examination}

Examination by electron microscope leaky sites of blood-brain barrier neurovessels demonstrated single or aggregating platelets sticking and adhering to the blood-brain barrier vessel walls 1 year after brain ischemia. Inside vessels aggregates of platelets predominated in blood-brain barrier neurovessels branches and bifurcations that correlated very well with blood-brain barrier permeability. Many microvessels were plugged by platelets what completely stopped blood flow. Additionally platelets were observed on the abluminal side of blood-brain barrier neurovessels. Platelets pathology was single, scattered and random. These kind of changes occurred in small arterioles, capillaries, venules and veins mainly of hippocampus, brain cortex and white matter. Platelet pathology and toxic parts of amyloid precursor protein correlated very well with blood-brain barrier changes. Above kind of pathology was not observed in sham-operated rats.

\section{Neuropathological examination}

In ischemic rats significant atrophy associated with diffuse selective and nonselective neuronal loss was evident in the bilateral brain cortex, basal ganglia and striatum in addition to CA1 sector of hippocampus (Fig. 1C). Long-term survival after brain ischemia results in chronic neuronal changes and death in hippocampus sectors of nonselective vulnerability like CA2, CA3 and CA4 areas. Striatal changes are mainly located in the dorsolateral area and influence medium-sized neurons. In the brain cortex, the layers 3, 5 and 6 presented neuronal pathology. Neuronal loss was superimposed with degenerating neurons, which at that time became even more intense and diffuse. The latter was localized in hippocampus, brain cortex and striatum. Borderline zones of the brain cortex were also the site of severe changes. One year after ischemia in addition to localized neuronal loss different types of degenerative changes of neurons were present. The first one took the form of chronic neurons degeneration and their calcification seemed to represent the residual stage of changes noted in the early postischemic period. Curiously other changes were of a nature typical for the early postischemic stage, but they appeared in those areas of the brain that were not involved early e.g. the CA2, CA3 and CA4 sectors of hippocampus. After ischemia disappearing neurons were replaced by naked astrocytic nuclei and glial nodules. Hypertrophic and proliferating astrocytes were localized in areas of mild and severe neuronal loss. In some animals mixed astrocytic microglial nodules were present. Within above areas of selective and nonselective neurons damages strong activity of astrocytes and microglia were noted. Gross pathological examination revealed hydrocephalic features of brain (Fig. 1C). They were expressed by almost complete atrophy of dorsal hippocampus (Fig. 1C) and striatum leading to enlargement of the ventricular system (Fig. 1C). Brain cortex in most regions was narrow showing increased neuronal density. White matter revealed advanced spongiosis leading to profound cavitations. These changes have been seen mainly in the subcortical and periventricular areas. Diffuse astrocytic proliferation in white and grey matter was observed. Above kind of pathology was not observed in sham-operated rats.

\section{Discussion}

The main finding of the present study is that as late as one year after the ischemic injury the atrophy of brain is still going with cognitive deficits as evidenced by a) creepy brain cells damage and death, b) neuroinflammation, c) blood-brain barrier leakage, d) platelets pathology which are main source of amyloid precursor protein and $\beta$-amyloid peptide in blood, e) $\beta$-amyloid peptide and C-terminal of amyloid precursor 
protein accumulation, f) the development of dementia features (Table 1). Ischemic brain injury increases the expression of amyloid precursor protein (Koistinaho et al. 1996, Shi et al. 2000, Nihashi et al. 2001). In addition to a net increase and accumulation of the amyloid protein, also upregulation of the proteolytic processing of APP in response to ischemia has been presented (Pluta et al. 1994c, Yokota et al. 1996, Lin et al. 1999, Nihashi et al. 2001, Badan et al. 2004, Yang and Simpkins 2007). Interestingly, transient brain ischemia has been shown to induce the expression of $\beta$-secretase (Wen et al. 2004a, Chuang et al. 2008, Ye et al. 2009) and $\gamma$-secretase (Polavarapu et al. 2008). Above increase was associated with markers of apoptosis suggesting yet another link between ischemia and subsequent neurodegeneration leading to dementia (Malm and Koistinaho 2007, Yang and Simpkins 2007). Aforementioned indicates that all $\beta$ amyloid-metabolism-related genes may participate in both the acute and chronic $\beta$-amyloid peptide generation following brain ischemia and promote chronic pathologic progress of brain ischemia (Pluta et al. 2009, 2010b, Ye et al. 2009). Several other laboratories have reported that ischemia induces the cleavage of amyloid precursor protein into $\beta$-amyloid peptide in vivo and that increased amyloid precursor protein cleavage results in the extracellular accumulation of $\beta$-amyloid peptide (Pluta et al. 1994c, Yokota et al. 1996, Lin et al. 1999, Bennett et al. 2000, Lee et al. 2006). $\beta$-amyloid peptide deposition in response to brain ischemia seems not to be a transient phenomenon, as $\beta$-amyloid peptide aggregates and even plaque-like structures were found in ischemic animals as late as 9 months after the ischemic injury (Van Groen et al. 2005). There are several factors that influence the increase in amyloid precursor protein expression as a result of ischemic insults. These include at least age, glucose and estrogens decrease (Shi et al. 1997, Simpkins et al. 1997, Wise et al. 2001, Badan et al. 2004). For instance, transient brain ischemia induces a higher increase in amyloid precursor protein expression with diminished functional recovery in old rats compared to young rats (Badan et al. 2004). The aberrant amyloid precursor protein processing into $\beta$-amyloid peptide probably is sufficient to induce neuronal dysfunction. This concept is supported by findings indicating that in fact, the oligomeric, soluble form of $\beta$-amyloid peptide is more neurotoxic than the aggregated, fibrillar form of $\beta$-amyloid peptide (Dahlgren et al. 2002). In addition, the appearance of $\beta$-amyloid peptide plaques is not required for the development cognitive deficits in amyloid precursor protein transgenic mice (Dodart et al. 1999, Koistinaho et al. 2002) .

Current investigations have been reported a sitespecific hyperphosphorylation of tau protein after brain ischemia in animals (Wen et al. 2004b, Yang and Simpkins 2007). Tau protein can be phosphorylated at serine and threonine residues by several different kinases (Avila 2006). Abnormal phosphorylation of tau protein leads to a loss of microtubule binding capacity and it is thought to contribute to the subsequent formation of neurofibrillary tangles. The hyperphosphorylated tau protein in ischemic female rats was found in neurofibrillary tangle-like conformational epitopes (Wen et al. 2007), the formation of which was preceded by signs of apoptosis in cortical neurons (Wen et al. 2004c).

Another link between ischemia-induced changes and the development of Alzheimer-related neuropathology is inflammation. Neuroinflammation undoubtedly is a major component in the maturation of ischemic brain injury (Koistinaho et al. 2002, Pluta et al. 2009, Andjus et al. 2010). Brain ischemia may also exacerbate Alzheimer-related inflammatory responses and therefore contribute to the progressive loss of neurons. In support of above, brain ischemic injury induces more severe inflammatory responses in amyloid precursor protein transgenic mice compared to their wild type littermates (Koistinaho et al. 2002). Ischemiainduced astrocytosis and microgliosis were also enhanced in rats receiving a fragment of $\beta$-amyloid peptide into the lateral ventricles compared to rats without $\beta$-amyloid peptide exposure (Whitehead et al. 2005).

Several lines of evidence also suggest that the integrity of blood-brain barrier contribute to the pathology of Alzheimer-type. Besides protecting the brain tissue from pathogens and toxic proteins in circulating blood stream, blood-brain barrier also actively participates in the clearance of soluble $\beta$-amyloid peptide from the brain into the blood stream, most likely via an LDL-receptor related protein-1 (Shibata et al. 2000, Ji et al. 2001). Blood-brain barrier becomes chronically impaired for small and big molecules in ischemic brain (Pluta et al. 1996, 2009, 2010a, Andjus et al. 2010) and similarly the presence of $\beta$-amyloid peptide in the vessel walls of Alzheimer patients may disrupt the proper function of blood-brain barrier, thereby altering the permeability of the blood-brain barrier to $\beta$-amyloid peptide (Pluta et al. 1996, 2010a, Zlokovic 2002). Taken together, data gathered from the studies in different animal models of ischemia suggest that ischemic injuries 
result in the aberrant processing of amyloid precursor protein, the enhancement of $\beta$-amyloid peptide production and abnormal tau phosphorylation (Table 1). These molecular events may contribute to the creepy neurodegeneration (Pluta et al. 2010a) and the development of cognitive impairment after ischemic insults (Table 1) (Jabłoński et al. 2010, Pluta et al. 2010c).

Strong body of evidence arising from the experimental models of brain ischemia suggests common cellular and molecular mechanisms between brain ischemia and Alzheimer disease. These studies demonstrate that ischemic injuries may have direct effects on the development of Alzheimer-related neuropathology (Table 1) and, on the other hand, Alzheimer disease linked pathological changes particularly in the expression of amyloid precursor protein, clearly render the neurons more vulnerable to ischemic insults (Koistinaho et al.
2002, Pluta et al. 2009) via complex mechanisms involving e.g. aggravated inflammatory responses and direct neurotoxic and synaptotoxic effects of $\beta$-amyloid peptide. These molecular links between brain ischemia and Alzheimer disease may offer relevant therapeutic targets for the prevention and treatment of neurodegeneration underlying the clinically detected dementia.

\section{Conflict of Interest}

There is no conflict of interest.

\section{Acknowledgements}

This study was supported in part by founds from: Mossakowski Medical Research Centre (T5), Polish Ministry of Science and Higher Education (2007-2010Cost/253/2006) and European Union (Cost Action B30).

\section{References}

AVILA J: Tau phosphorylation and aggregation in Alzheimer's disease pathology. FEBS Lett 580: 2922-2927, 2006.

ANDJUS PR, MICHETTI F, PLUTA R, BACIC G: Imaging the breakdown of the BBB and neuroinflammation in models of neurodegeneration. (Conference Abstract:) Pharmacology and Toxicology of the Blood-Brain Barrier: State of the Art, Needs for Future Research and Expected Benefits for the EU. Frontiers Conferences. Doi: 10.3389/conf.fphar.2010.02.00023 (1-3), 2010.

BADAN I, DINCA I, BUCHHOLD B, SUOFU Y, WALKER L, GRATZ M, PLATT D, KESSLER CH, POPAWAGNER A: Accelerated accumulation of N- and C-terminal beta APP fragments and delayed recovery of microtubule-associated protein 1B expression following stroke in aged rats. Eur J Neurosci 19: 2270-2280, 2004.

BENNETT SA, PAPPAS BA, STEVENS WD, DAVIDSON CM, FORTIN T, CHEN J: Cleavage of amyloid precursor protein elicited by chronic cerebral hypoperfusion. Neurobiol Aging 21: 207-214, 2000.

CHUANG CM, HSIEH CL, LIN HY, LIN JG: Panax Notoginseng Burk attenuates impairment of learning and memory functions and increases ED1, BDNF and beta-secretase immunoreactive cells in chronic stage ischemiareperfusion injured rats. Am J Chin Med 36: 685-693, 2008.

DAHLGREN KN, MANELLI AM, STINE WB JR, BAKER LK, KRAFFT GA, LADU MJ: Oligomeric and fibrillar species of amyloid-beta peptides differentially affect neuronal viability. J Biol Chem 277: 32046-32053, 2002.

DODART JC, MEZIANE H, MATHIS C, BALES KR, PAUL SM, UNGERER A: Behavioral disturbances in transgenic mice overexpressing the V717F beta-amyloid precursor protein. Behav Neurosci 113: 982-990, 1999.

HOSSMANN KA, SCHMIDT-KASTNER R, OPHOFF BG: Recovery of integrative central nervous function after one hour global cerebro-circulatory arrest in normothermic cat. J Neurol Sci 77: 305-320, 1987.

JABŁOŃSKI M, KIRYK A, UŁAMEK M, JANUSZEWSKI S, PLUTA R, KACZMAREK L: Animal model for human investigation and rehabilitation in Alzheimer type cognitive deficits. In: 6th World Congress of Neurorehabilitation International Proceedings. V HÖMBERG, H BINDER (eds), Medimond s.r.l., Bologna, Italy, 2010, pp 95-98.

JI Y, PERMANNE B, SIGURDSSON EM, HOLTZMAN DM, WISNIEWSKI T: Amyloid beta40/42 clearance across the blood-brain barrier following intra-ventricular injections in wild-type, apoE knock-out and human apoE3 or E4 expressing transgenic mice. J Alzheimers Dis 3: 23-30, 2001. 
KOISTINAHO J, PYYKONEN I, KEINANEN R, HOKFELT T: Expression of beta-amyloid precursor protein mRNAs following transient focal ischaemia. NeuroReport 7: 2727-2731, 1996.

KOISTINAHO M, KETTUNEN MI, GOLDSTEINS G, KEINANEN R, SALMINEN A, ORT M, BURES J, LIU D, KAUPPINEN RA, HIGGINS LS, KOISTINAHO J: Beta-amyloid precursor protein transgenic mice that harbor diffuse A beta deposits but do not form plaques show increased ischemic vulnerability: role of inflammation. Proc Natl Acad Sci U S A 99: 1610-1615, 2002.

LEE PH, HWANG EM, HONG HS, BOO JH, MOOK-JUNG I, HUH K: Effect of ischemic neuronal insults on amyloid precursor protein processing. Neurochem Res 31: 821-827, 2006.

LIN B, SCHMIDT-KASTNER R, BUSTO R, GINSBERG MD: Progressive parenchymal deposition of beta-amyloid precursor protein in rat brain following global cerebral ischemia. Acta Neuropathol 97: 359-368 1999.

MALM T, KOISTINAHO M: Relationships between brain ischemia and Alzheimer's disease - insights derived from preclinical animal models. In: Ischemia-Reperfusion Pathways in Alzheimer's Disease. R PLUTA (ed), Nowa Science Publishers, Inc., New York, 2007, pp 17-39.

NIHASHI T, INAO S, KAJITA Y, KAWAI T, SUGIMOTO T, NIWA M, KABEYA R, HATA N, HAYASHI S, YOSHIDA J: Expression and distribution of beta amyloid precursor protein and beta amyloid peptide in reactive astrocytes after transient middle cerebral artery occlusion. Acta Neurochir 143: 287-295, 2001.

PLUTA R: The role of apolipoprotein $\mathrm{E}$ in the deposition of $\beta$-amyloid peptide during ischemia-reperfusion brain injury. A model of early Alzheimer's disease. Ann NY Acad Sci 903: 324-334, 2000.

PLUTA R: Glial expression of the $\beta$-amyloid peptide in cardiac arrest. J Neurol Sci 203-204: 277-280, 2002.

PLUTA R: Ischemia-Reperfusion Pathways in Alzheimer's Disease. Nova Science Publishers, Inc., New York, 2007.

PLUTA R, LOSSINSKY AS, MOSSAKOWSKI MJ, FASO L, WIŚNIEWSKI HM: Reassessment of new model of complete cerebral ischemia in rats. Method of induction of clinical death, pathophysiology and cerebrovascular pathology. Acta Neuropathol 83: 1-11, 1991.

PLUTA R, LOSSINSKY AS, WALSKI M, WIŚNIEWSKI HM, MOSSAKOWSKI MJ: Platelet occlusion phenomenon after short- and long-term survival following complete cerebral ischemia in rats produced by cardiac arrest. $J$ Brain Res 35: 463-471, 1994a.

PLUTA R, LOSSINSKY AS, WIŚNIEWSKI HM, MOSSAKOWSKI MJ: Early blood-brain barrier changes in the rat following transient complete cerebral ischemia induced by cardiac arrest. Brain Res 633: 41-52, $1994 \mathrm{~b}$.

PLUTA R, KIDA E, LOSSINSKY AS, GOLABEK AA, MOSSAKOWSKI MJ, WISNIEWSKI HM: Complete cerebral ischemia with short-term survival in rats induced by cardiac arrest. I. Extracellular accumulation of Alzheimer's beta-amyloid protein precursor in the brain. Brain Res 649: 323-328, 1994c.

PLUTA R, BARCIKOWSKA M, JANUSZEWSKI S, MISICKA A, LIPKOWSKI AW: Evidence of blood- brain barrier permeability/leakage for circulating human Alzheimer's $\beta$-amyloid-(1-42)-peptide. NeuroReport 7: 1261-1265, 1996.

PLUTA R, UŁAMEK M, JABŁOŃSKI M: Alzheimer's mechanisms in ischemic brain degeneration. Anat Rec 292: 1863-1881, 2009.

PLUTA R, JANUSZEWSKI S, JABŁOŃSKI M, UŁAMEK M: Factors in creepy delayed neuronal death in hippocampus following brain ischemia-reperfusion injury with long-term survival. Acta Neurochir (Suppl) 106: 37-41, 2010a.

PLUTA R, UŁAMEK M, JABŁOŃSKI M: Consideration of the ischaemic basis and treatment of Alzheimer's disease. Folia Neuropathol 48: 11-26, 2010b.

PLUTA R, KIRYK A, UŁAMEK M, KACZMAREK L, JABŁOŃSKI M: An experimental model for the Alzheimer phenotype of cognitive deficits. (Conference Abstract:) Pharmacology and Toxicology of the Blood-Brain Barrier: State of the Art, Needs for Future Research and Expected Benefits for the EU. Frontiers Conferences. Doi:10.3389/conf.fphar.2010.02.00018 (1-4), 2010c.

POLAVARAPU R, AN J, ZHANG C, YEPES M: Regulated intramembrane proteolysis of the low-density lipoprotein receptor-related protein mediates ischemic cell death. Am J Pathol 172: 1355-1362, 2008.

SHI J, XIANG Y, SIMPKINS JW: Hypoglycemia enhances the expression of mRNA encoding beta-amyloid precursor protein in rat primary cortical astroglial cells. Brain Res 772: 247-251, 1997. 
SHI J, YANG SH, STUBLEY L, DAY AL, SIMPKINS JW: Hypoperfusion induces overexpression of beta-amyloid precursor protein mRNA in a focal ischemic rodent model. Brain Res 853: 1-4, 2000.

SHIBATA M, YAMADA S, KUMAR SR, CALERO M, BADING J, FRANGIONE B, HOLTZMAN DM, MILLER CA, STRICKLAND DK, GHISO J, ZLOKOVIC BV: Clearance of Alzheimer's amyloid-ss(1-40) peptide from brain by LDL receptor-related protein-1 at the blood-brain barrier. J Clin Invest 106: 1489-1499, 2000.

SIMPKINS JW, RAJAKUMAR G, ZHANG YQ, SIMPKINS CE, GREENWALD D, YU CJ, BODOR N, DAY AL: Estrogens may reduce mortality and ischemic damage caused by middle cerebral artery occlusion in the female rat. J Neurosurg 87: 724-730, 1997.

VAN GROEN T, PUURUNEN K, MAKI HM, SIVENIUS J, JOLKKONEN J: Transformation of diffuse beta-amyloid precursor protein and beta-amyloid deposits to plaques in the thalamus after transient occlusion of the middle cerebral artery in rats. Stroke 36: 1551-1556, 2005.

WEN Y, ONYEWUCHI O, YANG S, LIU R, SIMPKINS JW: Increased beta-secretase activity and expression in rats following transient cerebral ischemia. Brain Res 1009: 1-8, 2004a.

WEN Y, YANG S, LIU R, SIMPKINS JW: Transient cerebral ischemia induces site-specific hyperphosphorylation of tau protein. Brain Res 1022: 30-38, $2004 \mathrm{~b}$.

WEN Y, YANG S, LIU R, BRUN-ZINKERNAGEL AM, KOULEN P, SIMPKINS JW: Transient cerebral ischemia induces aberrant neuronal cell cycle re-entry and Alzheimer's disease-like tauopathy in female rats. $J$ Biol Chem 279: 22684-22692, 2004c.

WEN Y, YANG SH, LIU R, PEREZ EJ, BRUN-ZINKERNAGEL AM, KOULEN P, SIMPKINS JW: Cdk5 is involved in NFT-like tauopathy induced by transient cerebral ischemia in female rats. Biochim Biophys Acta 1772: 473483, 2007.

WHITEHEAD SN, HACHINSKI VC, CECHETTO DF: Interaction between a rat model of cerebral ischemia and betaamyloid toxicity: inflammatory responses. Stroke 36: 107-112, 2005.

WISE PM, DUBAL DB, WILSON ME, RAU SW, BOTTNER M: Minireview: neuroprotective effects of estrogen-new insights into mechanisms of action. Endocrinology 142: 969-973, 2001.

YANG SH, SIMPKINS JW: Ischemia-reperfusion promotes tau and beta-amyloid pathology and a progressive cognitive impairment. In: Ischemia-reperfusion pathways in Alzheimer's disease. R PLUTA (ed), Nowa Science Publishers, Inc, New York, 2007, pp 113-138.

YE J, PI R, MAO X, CHEN X, QIN J, XU S, LIU P: Alterations in mRNA expression of BACE1, cathepsin B, and glutaminyl cyclase in mice ischemic brain. NeuroReport 20: 1456-1460, 2009.

YOKOTA M, SAIDO TC, TANI E, YAMAURA I, MINAMI N: Cytotoxic fragment of amyloid precursor protein accumulates in hippocampus after global forebrain ischemia. J Cereb Blood Flow Metab 16: 1219-1223, 1996.

ZLOKOVIC BV: Vascular disorder in Alzheimer's disease: role in pathogenesis of dementia and therapeutic targets. Adv Drug Deliv Rev 54: 1553-1559, 2002. 